OPEN ACCESS

Edited by:

Bing Gu,

The Affiliated Hospital of Xuzhou

Medical University, China

Reviewed by:

Guo-Bao Tian,

Sun Yat-sen University, China

Hong Du,

Soochow University, China

*Correspondence:

Feng Gu

15852482679@126.com

Ying Yang

y_ying_77@163.com

tThese authors have contributed equally to this work and share first

authorship

Specialty section: This article was submitted to Antimicrobials, Resistance and Chemotherapy,

a section of the journal

Frontiers in Microbiology

Received: 25 January 2021 Accepted: 28 April 2021

Published: 20 May 2021

Citation:

Hu S, Zhu F, Jiang W, Wang Y, Quan Y, Zhang G, Gu F and Yang Y (2021) Retrospective Analysis of the

Clinical Characteristics of Candida auris Infection Worldwide From 2009 to 2020. Front. Microbiol. 12:658329.

doi: 10.3389/fmicb.2021.658329

\section{Retrospective Analysis of the Clinical Characteristics of Candida auris Infection Worldwide From 2009 to 2020}

\author{
Shan $\mathrm{Hu}^{1,2 t}$, Feilong Zhu ${ }^{3 t}$, Weiwei Jiang ${ }^{4 t}$, Yuehua Wang ${ }^{5}$, Yongqiang Quan ${ }^{6}$, \\ Guoming Zhang ${ }^{7}$, Feng $\mathrm{Gu}^{2 *}$ and Ying Yang ${ }^{1 *}$
}

\begin{abstract}
' Department of Biotechnology, Beijing Institute of Radiation Medicine, Beijing Key Laboratory of New Molecular Diagnosis Technologies for Infectious Diseases, Beijing, China, ${ }^{2}$ Department of Laboratory Medicine, Xuzhou Tumor Hospital, Xuzhou, China, ${ }^{3}$ The Affiliated Xuzhou Rehabilitation Hospital of Xuzhou Medical University, Xuzhou Rehabilitation Hospital, Xuzhou, China, ${ }^{4}$ Shanghai Key Laboratory of Molecular Medical Mycology, Shanghai Institute of Mycology, Shanghai Changzheng Hospital, Second Military Medical University, Shanghai, China, ${ }^{5}$ Department of Life Science, Hebei University, Baoding, China, ${ }^{6}$ Department of Nephrology, Affiliated Huaihai Hospital of Xuzhou Medical University, Xuzhou, China, ${ }^{7}$ Department of Laboratory Medicine, Shuyang People's Hospital, The Affiliated Shuyang Hospital of Xuzhou Medical University, Shuyang, China
\end{abstract}

Introduction: Candida auris is an emerging multidrug-resistant fungus that may cause infections with a high mortality rate. The first case of $C$. auris infection was reported in 2009 and infections have been reported in 44 countries. The fungus now represents a major global public health threat. We analyzed cases from the emergence of $C$. auris infections up until the end of 2020. It is hoped that the results of this analysis will raise awareness in scientists to promote protection and control research pertaining to this pathogen.

Methods: PubMed and Web of Science databases were searched for all papers related to C. auris infections up until December 31, 2020. We sorted and organized these data into the following categories: date of publication, patient age and sex, underlying diseases, risk factors for infection, patient mortality information, drug sensitivity information of $C$. auris isolates, and genetic classification. The $\chi^{2}$ test was used to screen for factors that may affect patient mortality.

Results: A total of 912 patients were included in the analysis. There's a higher proportion of men and a high proportion of patients were premature babies and elderly people. The proportions of patients with underlying diseases such as diabetes, kidney disease, trauma, and ear disease were also high. More than half of patients had a history of central venous catheter use and a history of broad-spectrum antibiotic use. The $\chi^{2}$ test revealed that only kidney disease $(P<0.05)$ was an important risk factor for mortality in C. auris-infected patients. 
Conclusions: A comprehensive understanding of C. auris was achieved following this retrospective analysis, including the characteristics of $C$. auris-infected patients. In recent years, increasing numbers of multidrug-resistant $C$. auris isolates have been identified, and the high mortality rates associated with infection merit greater attention from the medical world.

Keywords: Candida auris, infection characteristics, underlying disease, drug resistance, risk factor for mortality

\section{INTRODUCTION}

Since 2009, when the first Candida auris infection case was reported in Japan (Satoh et al., 2009), until December 31, 2020, C. auris infections have been reported in 44 countries globally (Centers for Disease Control and Prevention, 2021). In April 2019, the New York Times reported a multidrug-resistant fungal infection outbreak in many parts of the United States. The causative agent of this outbreak was $C$. auris; however, the aforementioned article referred to the infections as "mysterious infections" and deemed the outbreak an "urgent threat." Nearly $50 \%$ of infected individuals died within 90 days and the outbreak subsequently attracted widespread global attention (The New York Times, 2019). Because of the associated high mortality rates, $C$. auris can now be considered a major global public health threat (Meis and Chowdhary, 2018).

Before 2009, C. auris was thought to be a rarely observed microorganism. It is now deemed an emerging human pathogen (Rhodes and Fisher, 2019). C. auris can colonize different sites, such as the skin, axilla, nose, and groin, and is transmitted by contact or through feces. In addition, the pathogen can survive on inanimate object surfaces for more than 7 days (Calvo et al., 2016; Biswal et al., 2017). Therefore, hospital beds, sphygmometers, thermometers, and other reusable equipment are potential infection sources for inpatients. This has resulted in relatively high rates of $C$. auris transmission in inpatients, particularly in ICU rooms (Madder et al., 2017; Ku et al., 2018). This latter phenomenon has led to a vicious cycle of acquisition, transmission, and infection (Cortegiani et al., 2019). It is difficult to eradicate $C$. auris once it has colonized a patient, and colonization of patients can last for three or more continuous months (Jeffery-Smith et al., 2018). Even though many countries have implemented infection prevention and control (IPC) strategies, C. auris transmission is still a problem that warrants attention.

The appearance of multidrug resistance (MDR) in C. auris is another problem that has attracted global attention in recent years (Kathuria et al., 2015). The sensitivity of many C. auris isolates toward fluconazole has decreased and associated strains have developed varying degrees of resistance to other antifungal drugs (Chowdhary et al., 2017). Public health guidelines recommend that echinocandins (micafungin, caspofungin, and anidulafungin) should be used as first-line treatments for C. auris infections (Chowdhary et al., 2016; Kim Hutchings Uke, 2018). However, the continuous evolution of C. auris has resulted in echinocandin resistance. Indeed, the minimum inhibitory concentrations (MIC) of azoles, amphotericin B, and echinocandin toward some isolates have even increased (Rhodes et al., 2018). Therefore, close attention to the evolution of C. auris is required.

Traditional identification techniques cannot be used to identify C. auris. Therefore, the prevalence of C. auris infections in the global population remains unknown. C. auris has resulted in an "invisible pandemic" due to its broad nosocomial infection range (Jeffery-Smith et al., 2018). Thus, it is extremely important to comprehensively understand the characteristics of C. auris itself along with the patients that the fungus infects. With this in mind, we collected papers since the first report of $C$. auris and extracted information pertaining to the patients' age and sex, underlying diseases, possible risk factors that may induce infection, genetic phenotype classification of $C$. auris isolates, drug susceptibility information, and drug resistance loci. We compiled this information and conducted a statistical analysis to identify new infection-related characteristics. The mortality rate of $C$. auris infection in patients is an important factor that threatens global public health (Meis and Chowdhary, 2018). Therefore, this study employed a conservative regression model to determine the effects of several factors on patient mortality. We believe that this analysis and summary of the relevant data will result in a greater public understanding of $C$. auris infections, thereby enabling scientists to focus greater attention on the evolution of multidrug resistance in C. auris.

\section{MATERIALS AND METHODS}

\section{Case Inclusion}

PubMed and Web of Science were used to conduct the literature search using the following search criteria: 1. titles or abstracts containing the keyword $C$. auris; and 2. time range with an unlimited start date and an end date of December 31, 2020. A total of 580 papers were identified through the literature search. Experimental study papers were excluded while case reports were selected for the analysis. Of these, 146 papers reporting $C$. auris cases were included; these reports involved nearly 6,000 patients.

The papers were organized and analyzed after case screening. First, repeated cases were excluded: suspected repetitive cases from the same year and country were excluded based on isolate number, detection time, and detection institution; cases with incomplete information were excluded; and cases identified as infection caused by colonized $C$. auris were excluded. The data of 912 cases were included in the statistical analysis. 


\section{Data Entry}

The following information required for analysis was input:

In order to ensure the accuracy of analysis, each dataset required review by at least three members of the team before it was accepted. In this study, the Beijing Key Laboratory for Molecular Diagnostics of Infectious Diseases was deemed the leading site and it established a research team consisting of one clinician, two laboratory physicians, one medical mycology researcher, and one pharmacology researcher.

\section{Data Organization and Statistical Analysis}

In this study, underlying diseases predominantly included systemic diseases, comorbid infections, and organ diseases; these were further divided into 52 subcategories. Suspected patients were not included in the statistics.

In order to avoid the repetition of statistical analyses pertaining to drug sensitivity data, the most recent data for an isolate were used when the same method was employed to analyze more than one drug sensitivity experiment. Interestingly, the MIC values for the most recent results generated from drug sensitivity experiments in all papers were the highest. When the broth method and standard commercial reagents were both used for drug sensitivity experiments for the same isolate, the drug sensitivity results obtained using standard commercial reagents were chosen for analysis. When different standard commercial drug sensitivity test systems $\left(\mathrm{VITEK}^{\circledR} 2\right.$ and Sensititre ${ }^{\circledR}$ YeastOne ${ }^{\circledR}$ were used in this study) were used for the same isolate, the test results from the VITEK ${ }^{\circledR} 2$ system were selected as the inter-laboratory consistency of VITEK ${ }^{\circledR} 2$ was higher than that for Sensititre ${ }^{\circledR}$ YeastOne $^{\circledR}$ (Farina et al., 2011).

The mortality rate of $C$. auris infection is an important factor that threatens global public health. Hence, in this study we felt that it was important to screen for factors that affected patient mortality. We first extracted the information from all the cases in the literature, excluded the cases that missed important data, and included the cases with complete data in the analysis. The $\chi^{2}$ test was used for univariate analysis of the final complete cases to identify indicators that had a significant association with the outcome (Peduzzi et al., 1996). If the $P$-values of multiple indicators were less than 0.05 , these indicators were included in a multivariate regression model, and P-value correction was carried out to find the significant indicators under the influence of multiple factors (Hosmer et al., 2013). Otherwise, multivariate analysis was not performed (Mejia-Chew et al., 2019).

\section{RESULTS}

\section{Initial Infection Reports in Different Countries}

Since 2009 when $C$. auris was first isolated from an auditory canal of a patient in Japan, infections have also been reported in South Korea (Oh et al., 2011), India (Chowdhary et al., 2013), South Africa (Rindidzani et al., 2014), and Kuwait (Emara et al., 2015). After 2016, the number of countries reporting their first cases of C. auris infection began to increase. In 2018, 14 countries reported C. auris infections for the first time. This was the highest number of countries reporting infections for the first time in 12 years (shown in Figure 1).

\section{Genetic Classification of Isolates Detected in Various Countries}

The isolates detected by various countries were classified by whole genome sequencing data into South Asia strains (clade I), East Asia strains (clade II), South Africa strains (clade III), and South America strains (clade IV). The South Asia strains (clade I) were the most prevalent (17 countries), followed by the South Africa strains (clade III), which were observed in eight countries. Only five and three countries reported the presence of the East Asia strains (clade II) and the South America strains (IV), respectively. Both South Asia and South Africa strains simultaneously occurred in China, Germany, United Kingdom, and Saudi Arabia. All four clades appeared in the United States, a phenomenon that may be due to the large population movements. In addition, an isolate identified in Iran in 2019 may represent a potential clade V strain (shown in Figure 1; Nancy et al., 2019).

\section{Patient Sex and Age Distribution}

For the included patients, sex was mentioned for 827 patients, of which 508 (61.4\%) were male and 319 (38.6\%) were female, there's a higher proportion of men. This is shown in Figure 2A.

The World Health Organization age group classification criteria (Hosmer et al., 2013) were used to divide patients into children (0-18 years), adolescents (19-44 years), middle-aged (45-59 years), and elderly ( $\geq 60$ years). Figure $2 \mathbf{B}$ shows the age distribution of 279 cases in which age was mentioned. Approximately half of the population $(n=133,47.7 \%)$ were elderly. Thirty-two of the patients were infants less than 1 month old; 26 of the 32 (81.25\% of the infant population) patients were premature infants.

\section{Underlying Disease and Infected Population}

Underlying diseases were mentioned for 748 patients, of which the highest proportion of underlying diseases were diabetes, kidney disease (some had diabetic nephropathy), trauma, and ear disease. It should be noted that 10 patients also had COVID-19 (as shown in Table 1).

\section{Risk Factors That May Lead to Infection and Infected Population}

Risk factors for infection were mentioned for 773 patients (Table 2). Greater than $50 \%$ of patients had a history of broadspectrum antibiotic use and a history of central venous catheter use. These factors represent high risk factors for C. auris infection and are consistent with the risk factors espoused by global experts in relation to $C$. auris emergence and transmission (Hosmer et al., 2013). 

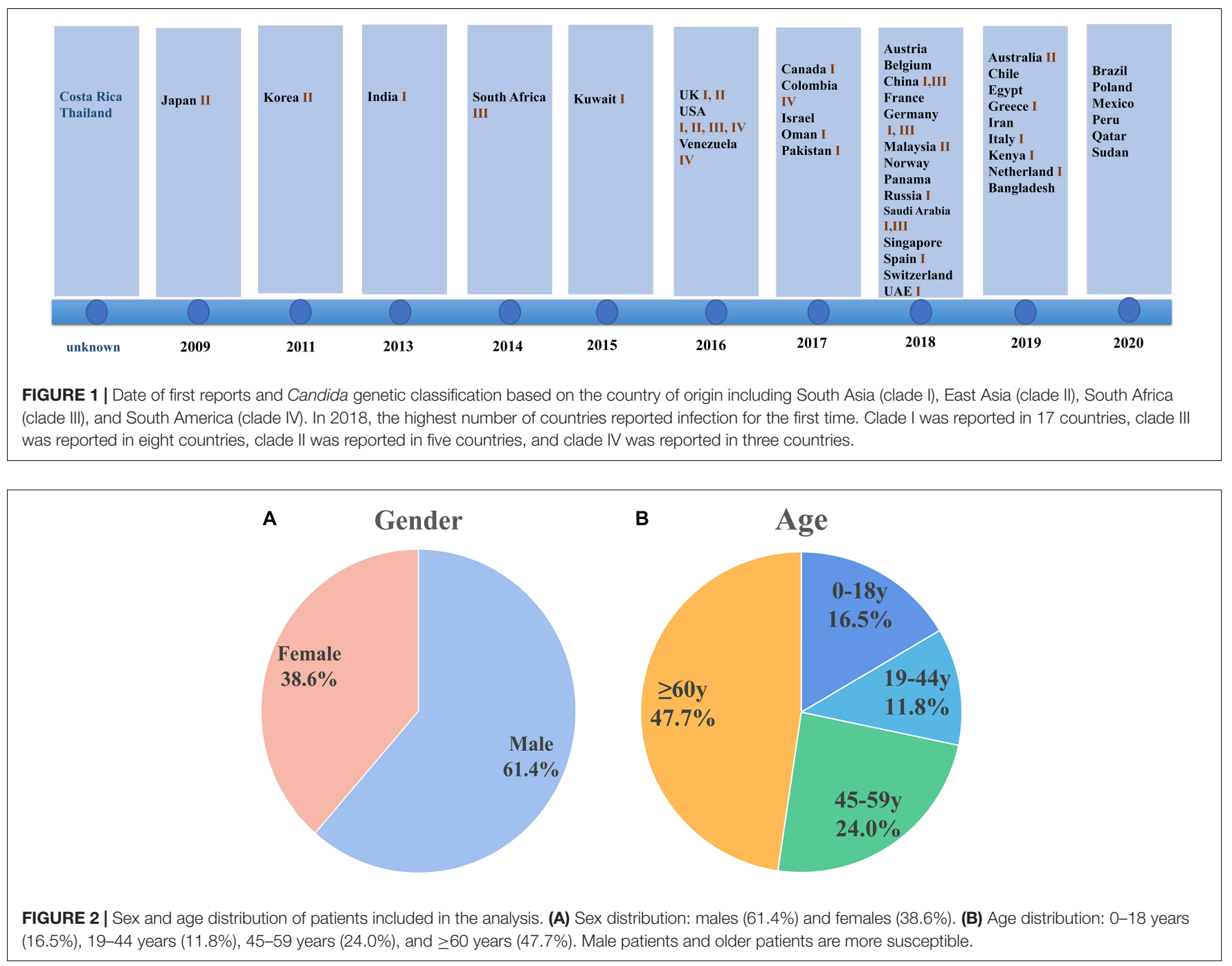

\section{Drug-Resistant Candida auris Strains}

Large differences in efficacy were observed for antifungal drugs in relation to the treatment of infection of different C. auris isolates (Chowdhary et al., 2017). The United States Centers for Disease Control (CDC) defined conservative cutoff points to determine whether C. auris is resistant to antifungals: fluconazole (FLC): $32 \mu \mathrm{g} / \mathrm{mL}$, amphotericin B (AMB): $2 \mu \mathrm{g} / \mathrm{mL}$, micafungin (MFG): $4 \mu \mathrm{g} / \mathrm{mL}$, and caspofungin (CAS): $2 \mu \mathrm{g} / \mathrm{mL} .^{2}$ In another study by the United States CDC, break points for voriconazole (VRC, $2 \mu \mathrm{g} / \mathrm{mL}$ ), anidulafungin (AFG, $4 \mu \mathrm{g} / \mathrm{mL}$ ), and flucytosine $(5-\mathrm{FC}, 32 \mu \mathrm{g} / \mathrm{mL}$ ) were established. A MIC < cutoff was defined as sensitive while a MIC $\geq$ cutoff was defined as resistant (Lockhart et al., 2016). Among the isolates that were included in the analysis, drug resistance information was available for 544 isolates; the proportion of isolates exhibiting FLC resistance was the highest (79.6\%), while isolates exhibiting $\mathrm{AMB}(34.8 \% \%)$ and VRC (23.3\%) resistance were the second and third most prevalent, respectively (Figure 3A). Among the VRC-resistant isolates, 18 Venezuelan isolates reported by Calvo et al. (2016). and eight United States isolates reported by Park et al. (2019) were completely resistant to VRC. Among the AMB-resistant isolates, five Qatar isolates that were reported by A Shaukat et al. (2020) were completely resistant to AMB.

Minimum inhibitory concentrations information was accessible for 172 isolates in the literature. This information was used to determine drug resistance (Figure 3B). Among these isolates, 18 isolates $(10.5 \%)$ were sensitive, 72 isolates $(41.9 \%)$ were resistant to one antifungal, 55 isolates $(32.0 \%)$ were resistant to two antifungals, 20 isolates (11.6\%) were resistant to three antifungals, four isolates (2.3\%) were resistant to five antifungals, and three isolates $(1.7 \%)$ were resistant to six antifungals. It should be noted that sensitive isolates were retrieved from six dead patients and the only one sensitive isolate was isolated from a surviving patient. Three isolates were resistant to six drugs (FLC, VRC, AMB, CAS, MFG, and AFG) and these isolates were obtained from three dead patients from the United States (Ostrowsky et al., 2020). Currently, echinocandin is the firstline drug for C. auris infection (Chowdhary et al., 2016; Kim Hutchings Uke, 2018). 
TABLE 1 | Underlying diseases in C. auris-infected patients.

\begin{tabular}{|c|c|c|}
\hline Underlying disease & $\begin{array}{l}\text { Number of } \\
\text { patients }\end{array}$ & $\begin{array}{l}\text { Proportion of } \\
\text { patients }\end{array}$ \\
\hline Diabetes & 149 & $19.9 \%$ \\
\hline Kidney disease & 138 & $18.4 \%$ \\
\hline Trauma & 91 & $12.2 \%$ \\
\hline Ear disease & 74 & $9.9 \%$ \\
\hline Lung disease & 63 & $8.4 \%$ \\
\hline Hypertension & 58 & $7.8 \%$ \\
\hline Tumor & 53 & $7.1 \%$ \\
\hline Brain disease & 47 & $6.3 \%$ \\
\hline Brain disease & 46 & $6.1 \%$ \\
\hline Liver disease & 25 & $3.3 \%$ \\
\hline Intestinal disease & 23 & $3.1 \%$ \\
\hline Urinary tract diseases & 21 & $2.8 \%$ \\
\hline Hematologic disease & 15 & $2.0 \%$ \\
\hline Nervous system disease & 13 & $1.7 \%$ \\
\hline $\begin{array}{l}\text { Acquired immunodeficiency } \\
\text { syndrome (AIDS) }\end{array}$ & 12 & $1.6 \%$ \\
\hline Vasculopathy & 10 & $1.3 \%$ \\
\hline COVID-19 & 10 & $1.3 \%$ \\
\hline Chemotherapy & 9 & $1.2 \%$ \\
\hline Thyroid disorder & 9 & $1.2 \%$ \\
\hline Pancreatic disease & 9 & $1.2 \%$ \\
\hline Other diseases & 71 & $9.5 \%$ \\
\hline
\end{tabular}

Other diseases are underlying disease categories with proportion of patients $<1 \%$.

TABLE 2 | Risk factors involved with C. auris-infected patients.

\begin{tabular}{lcc}
\hline Risk factor & $\begin{array}{c}\text { Number of } \\
\text { patients }\end{array}$ & $\begin{array}{c}\text { Proportion of } \\
\text { patients }\end{array}$ \\
\hline $\begin{array}{lcc}\text { Broad-spectrum antibiotic } \\
\text { treatment }\end{array}$ & 432 & $55.9 \%$ \\
Central venous catheter & 426 & $55.1 \%$ \\
ICU & 378 & $48.9 \%$ \\
Urinary catheter & 294 & $38.0 \%$ \\
Surgery & 287 & $37.1 \%$ \\
Treatment with antifungal drugs & 216 & $27.9 \%$ \\
before testing positive & & $26.4 \%$ \\
Mechanical ventilation & 204 & $17.3 \%$ \\
Immunosuppressant & 134 & $14.0 \%$ \\
Parenteral nutrition & 108 & $10.5 \%$ \\
Steroid treatment & 81 & $5.8 \%$ \\
Blood transfusion & 45 & $1.7 \%$ \\
Neutropenia & 13 & \\
\hline
\end{tabular}

\section{Drug Resistance Loci}

Among the isolates reported to date, the major drug resistance loci for azoles are ERG11, CDR1, and MDR1 (Healey et al., 2018; Kordalewska et al., 2018; Rybak et al., 2019); the major drug resistance loci for AMB are ERG 2, 3, 5, 6, or 11 (Rhodes et al., 2018); and the major drug resistance locus for echinocandin is FKS11 (Chowdhary et al., 2018; Hou et al., 2019). As part of a mechanistic analysis of drug resistance toward 5FC, Rhodes et al. (2018) sequenced the entire genome of 5FC-resistant C. auris and found an amino acid substitution in F211I in the FUR1 gene. However, further studies are required.

\section{Mortality Rate}

A total of 476 cases reported whether patients died or survived upon discharge. Among the latter cases, 226 died and the mortality rate was $47.5 \%$. Major causes of death that were mentioned included sepsis, septic shock, and multiorgan failure.

\section{Risk Factor for Mortality}

A total of 167 related cases were collected by literature retrieval, and 144 cases were included for analysis after excluding those missing important information. Based on the above univariate analysis, it was found that kidney disease was an important factor associated with mortality, with $P=0.029$ for patients with kidney disease (Table 3). The other indexes had no significant associations with mortality. Therefore, multivariate logistic regression model was not performed (Palazón-Bru et al., 2017).

\section{DISCUSSION}

Candida auris is an emerging pathogen and there is currently only a limited understanding of the mechanisms and risk factors that underpin associated infections. Hence, further studies are required to help scientists better understand this pathogen. During the early stages of emergence of a pathogen, information release along with medical and public health awareness are extremely important.

In this analysis of collected literature, incomplete information was available for many patients. The main reason for these gaps in information relate to the fact that C. auris isolates from these patients were not isolated during hospitalization but a few years later by public health institutions and research institutions during retrospective screening of samples. Many medical institutions still rely on culture to identify microorganisms (Navalkele et al., 2017). C. auris is closely related to Candida haemulonii and Candida pseudohaemulonii. They are extremely close in phylogeny, and it is difficult to distinguish them by phenotype. Thus, traditional identification methods such as Vitek 2 and API 20CAUX tend to incorrectly identify C. auris as these two close relatives (Kathuria et al., 2015). Although the development of matrix-assisted laser desorption/ionization time-of-flight mass spectrometry (MALDI-TOF MS) (Vatanshenassan et al., 2019) and sequencing (Muñoz et al., 2018) strategies have helped in the rapid and accurate diagnosis of C. auris, most parts of the world do not have the infrastructure to carry out these techniques. In addition, it is likely that there is a large volume of unpublished data pertaining to $C$. auris infections and the number of infected patients may be far higher than that reported in the literature. Therefore, this is an "invisible pandemic" (Jeffery-Smith et al., 2018).

In this retrospective analysis, we found that there's a higher proportion of male patients. The proportion of C. auris patients with diabetes, kidney disease, trauma, and ear disease is high. Jung et al. (Mejia-Chew et al., 2019) reported that 69 out of 79 C. auris infection patients had ear disease and their symptoms were relatively mild. Therefore, otolaryngology outpatient departments should be highly vigilant for C. auris 
A

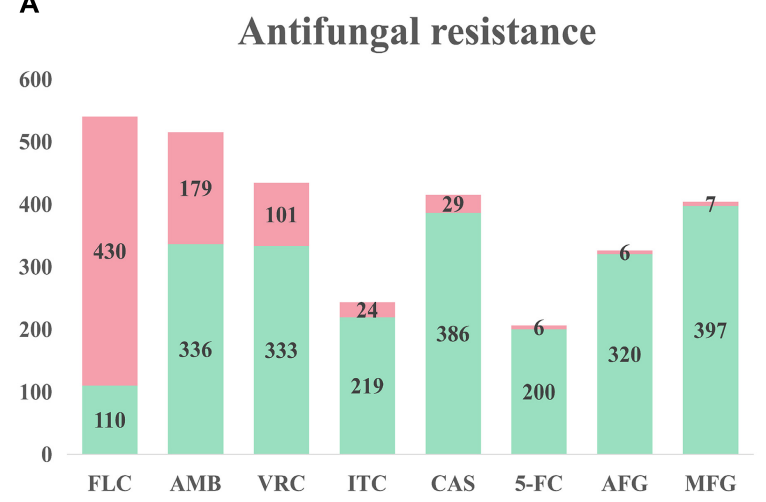

B

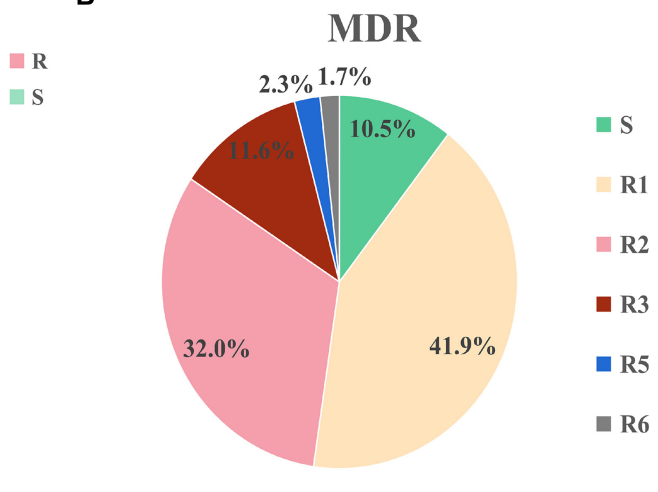

FIGURE 3 | Drug resistance of Candida auris isolates. (A) Drug resistance of Candida auris against eight common antifungals. The isolates had severe resistance to azoles and amphotericin B, and low resistance to echinomycin. (B) Drug resistance of Candida auris isolates. MDR: multi-drug resistance. S: sensitive, R1-R6: drug resistance status. Isolates had severe multidrug resistance, with some isolates exhibiting resistance to six antifungal agents.

infections. Among the C. auris patient population, $18.4 \%$ had kidney disease. Most of these patients had chronic kidney disease or nephrotic syndrome. More importantly, kidney disease is also an important risk factor that affects mortality in C. auris infection patients. Nephrologists should be extremely vigilant for C. auris infection. The reasons for the association of kidney disease with mortality may include the frequent use of immunosuppressants in the treatment process of patients with kidney disease; (Wang et al., 2019) the fact that most patients with kidney disease have low protein and malnutrition, which leads to a decline in immunity (Rhee et al., 2018); the fact that patients with kidney disease often suffer from diabetes (Alicic et al., 2017); and the dialysis treatments required by many patients with kidney disease (Collister et al., 2017). As the high infection rate in kidney disease patients is specific to $C$. auris compared with other Candida species, nephrologists in many regions do not have a high awareness of $C$. auris infections. Many nephrologists do not completely understand C. auris. Therefore, it is important that $C$. auris-related information be disseminated to various medical units, particularly nephrology departments, which can be extremely important in the early diagnosis of C. auris infections. In addition, although ICUs have been a focus of attention since $C$. auris was first reported, overall vigilance in ICUs is still not very strong and there is a need to strengthen knowledge gaps pertaining to prevention, diagnosis, and treatment knowledge.

Fluconazole exhibits broad-spectrum antifungal activity, good efficacy, a low incidence of adverse reactions, and appropriate plasma concentrations for long durations (Agrawal et al., 1996). $C$. auris has a high FLC resistance rate and the overall drug resistance ratio has been as high as $79.6 \%$ over the last 12 years. Thus, FLC is not recommended as an empiric drug therapy when treatment is urgent and drug sensitivity results have yet to be released for patients who either have been infected with C. auris or are suspected to have been infected with $C$. auris.

We did identify some areas for attention after an in-depth analysis of multidrug resistance in C. auris. Among the isolates for which patient mortality could be determined, sensitive ones were isolated from six dead patients and only one sensitive isolate was obtained from a surviving patient. We analyzed the possible reasons for the dearth of information pertaining to isolates causing mortality and speculated that virulence and mortality rates are higher when the $C$. auris isolate is sensitive (Tan et al., 2019; Lara et al., 2020). Sensitive isolates can be treated with antifungal drugs, thus clinical outcomes can be changed if the patients are diagnosed early and treated in a timely manner.

In addition, among the acquired data, three isolates that were resistant to six drugs were obtained and isolated from patients from the United States, where the outcome was death. Therefore, when multidrug resistance in C. auris gradually evolves, there will be situations where patients cannot be treated by drugs and death will occur. Echinocandin is currently the recommended treatment for C. auris (Kordalewska et al., 2018). If $C$. auris gradually evolves, more and more strains will develop echinocandin resistance and this may lead to an increase in the mortality rate of patients with C. auris infections. Although SCY078 (Larkin et al., 2017) and other new drugs have shown some promise, they have not been widely used in clinical practice. It is especially important to develop new drugs to combat high levels of echinocandin resistance.

There are some limitations pertaining to this study. As this is a retrospective analysis of published studies, there may be some original studies where the authors believed the associated conditions were not important and some of the risk factors were not mentioned. Thus, these papers were not included in this current analysis. As there was only a limited number of patients with certain diseases, there might be a selection bias in this study.

\section{CONCLUSION}

This retrospective analysis provides us with a greater understanding of C. auris, along with some of the main characteristics associated with $C$. auris-infected patients. In addition, an ever-increasing number of multidrug resistant 
TABLE $3 \mid \chi^{2}$ test screening of single factors that may be associated with patient mortality.

\begin{tabular}{|c|c|c|c|c|}
\hline Factor & & $\begin{array}{l}\text { Number of } \\
\text { deaths }\end{array}$ & $\begin{array}{c}\text { Number of } \\
\text { survived } \\
\text { patients }\end{array}$ & $P$-value \\
\hline \multirow[t]{2}{*}{ Sex } & Male & 46 & 47 & 0.340 \\
\hline & Female & 21 & 30 & \\
\hline \multirow[t]{2}{*}{ Sepsis } & Absent & 55 & 69 & 0.193 \\
\hline & Present & 12 & 8 & \\
\hline \multirow[t]{2}{*}{ Fever } & Absent & 59 & 67 & 0.850 \\
\hline & Present & 8 & 10 & \\
\hline \multirow[t]{2}{*}{ Ear disease } & Absent & 67 & 76 & 0.349 \\
\hline & Present & 0 & 1 & \\
\hline \multirow[t]{2}{*}{ Diabetes } & Absent & 46 & 54 & 0.848 \\
\hline & Present & 21 & 23 & \\
\hline \multirow[t]{2}{*}{ Hypertension } & Absent & 55 & 62 & 0.810 \\
\hline & Present & 12 & 15 & \\
\hline \multirow[t]{2}{*}{ Hypotension } & Absent & 66 & 76 & 0.921 \\
\hline & Present & 1 & 1 & \\
\hline \multirow[t]{2}{*}{ Hyperlipidemia } & Absent & 66 & 76 & 0.921 \\
\hline & Present & 1 & 1 & \\
\hline \multirow[t]{2}{*}{ Lung disease } & Absent & 46 & 61 & 0.148 \\
\hline & Present & 21 & 12 & \\
\hline \multirow[t]{2}{*}{ Tracheal disease } & Absent & 65 & 76 & 0.480 \\
\hline & Present & 2 & 1 & \\
\hline \multirow[t]{2}{*}{ Intestinal disease } & Absent & 60 & 70 & 0.784 \\
\hline & Present & 7 & 7 & \\
\hline \multirow[t]{2}{*}{ Kidney disease } & Absent & 41 & 60 & 0.029 \\
\hline & Present & 26 & 17 & \\
\hline \multirow[t]{2}{*}{ Liver disease } & Absent & 59 & 73 & 0.144 \\
\hline & Present & 8 & 4 & \\
\hline \multirow[t]{2}{*}{ Gallbladder disease } & Absent & 66 & 76 & 0.921 \\
\hline & Present & 1 & 1 & \\
\hline \multirow[t]{2}{*}{ Tumor } & Absent & 56 & 68 & 0.413 \\
\hline & Present & 11 & 9 & \\
\hline \multirow[t]{2}{*}{ Chemotherapy } & Absent & 65 & 76 & 0.480 \\
\hline & Present & 2 & 1 & \\
\hline \multirow{2}{*}{$\begin{array}{l}\text { Nasopharyngeal } \\
\text { disease }\end{array}$} & Absent & 65 & 77 & 0.127 \\
\hline & Present & 2 & 0 & \\
\hline \multirow[t]{2}{*}{ Laryngeal disease } & Absent & 66 & 77 & 0.282 \\
\hline & Present & 1 & 0 & \\
\hline \multirow[t]{2}{*}{ Hematologic disease } & Absent & 63 & 73 & 0.839 \\
\hline & Present & 4 & 4 & \\
\hline \multirow[t]{2}{*}{ Heart disease } & Absent & 52 & 66 & 0.207 \\
\hline & Present & 15 & 11 & \\
\hline \multirow[t]{3}{*}{ Neuropathy } & Absent & 73 & 87 & 0.127 \\
\hline & Present & 65 & 77 & \\
\hline & Present & 2 & 0 & \\
\hline \multirow[t]{2}{*}{ Vasculopathy } & Absent & 64 & 73 & 0.842 \\
\hline & Present & 3 & 4 & \\
\hline Abnormal coagulation & Absent & 65 & 76 & 0.480 \\
\hline & Present & 2 & 1 & \\
\hline Thyroid disorder & Absent & 63 & 76 & 0.127 \\
\hline & Present & 4 & 1 & \\
\hline
\end{tabular}

(Continued)
TABLE 3 | Continued

\begin{tabular}{|c|c|c|c|c|}
\hline Factor & & $\begin{array}{c}\text { Number of } \\
\text { deaths }\end{array}$ & $\begin{array}{c}\text { Number of } \\
\text { survived } \\
\text { patients }\end{array}$ & $P$-value \\
\hline \multirow[t]{2}{*}{ Drug abuse } & Absent & 67 & 76 & 0.349 \\
\hline & Present & 0 & 1 & \\
\hline \multirow[t]{4}{*}{ AIDS } & Absent & 65 & 75 & 0.888 \\
\hline & Present & 2 & 2 & \\
\hline & Present & 0 & 0 & \\
\hline & Present & 1 & 0 & \\
\hline \multirow[t]{2}{*}{ COVID-19 } & Absent & 61 & 73 & 0.376 \\
\hline & Present & 6 & 4 & \\
\hline \multirow[t]{2}{*}{ Pancreatic Disease } & Absent & 67 & 75 & 0.184 \\
\hline & Present & 0 & 2 & \\
\hline \multirow[t]{2}{*}{ Bone marrow disease } & Absent & 65 & 75 & 0.888 \\
\hline & Present & 2 & 2 & \\
\hline \multirow[t]{2}{*}{ Oral disease } & Absent & 67 & 76 & 0.349 \\
\hline & Present & 0 & 1 & \\
\hline \multirow[t]{2}{*}{ Urinary tract disease } & Absent & 64 & 74 & 0.862 \\
\hline & Present & 3 & 3 & \\
\hline \multirow[t]{2}{*}{ Endometrial disease } & Absent & 67 & 76 & 0.349 \\
\hline & Present & 0 & 1 & \\
\hline \multirow[t]{3}{*}{ Cytomegalovirus (CMV) } & Absent & 73 & 86 & 0.480 \\
\hline & Present & 65 & 76 & \\
\hline & Present & 2 & 1 & \\
\hline \multirow[t]{2}{*}{ Psychiatric disorder } & Absent & 66 & 75 & 0.643 \\
\hline & Present & 1 & 2 & \\
\hline \multirow[t]{2}{*}{ Psoriasis } & Absent & 66 & 77 & 0.282 \\
\hline & Present & 1 & 0 & \\
\hline \multirow[t]{2}{*}{ Pressure ulcer } & Absent & 64 & 74 & 0.842 \\
\hline & Present & 3 & 3 & \\
\hline \multirow[t]{2}{*}{ Asthma } & Absent & 66 & 77 & 0.282 \\
\hline & Present & 1 & 0 & \\
\hline \multirow[t]{2}{*}{ Adrenal glands } & Absent & 67 & 76 & 0.349 \\
\hline & Present & 0 & 1 & \\
\hline \multirow[t]{2}{*}{ Prostate gland } & Absent & 66 & 77 & 0.282 \\
\hline & Present & 1 & 0 & \\
\hline \multirow[t]{3}{*}{ Breasts } & Absent & 75 & 86 & 0.349 \\
\hline & Present & 67 & 76 & \\
\hline & Present & 0 & 1 & \\
\hline \multirow[t]{3}{*}{ Bone fracture } & Absent & 74 & 66 & 0.134 \\
\hline & Present & 66 & 72 & \\
\hline & Present & 1 & 5 & \\
\hline \multirow[t]{2}{*}{ Trauma } & Absent & 62 & 73 & 0.575 \\
\hline & Present & 5 & 4 & \\
\hline Age \# & & $64(31-74)$ & 53(32.5-72) & 0.172 \\
\hline
\end{tabular}

isolates have been identified and we should be vigilant in relation to the evolution of drug resistance in C. auris. It is important that we comprehensively improve diagnosis and treatment awareness for $C$. auris. We should actively develop early diagnostic techniques along with safe and effective drugs for the treatment of C. auris infections. 


\section{DATA AVAILABILITY STATEMENT}

The original contributions presented in the study are included in the article/supplementary material, further inquiries can be directed to the corresponding author/s.

\section{AUTHOR CONTRIBUTIONS}

YY and FG conceived and designed the study. SH, WJ, YW, and YQ collated and collected data. FZ and GZ did

\section{REFERENCES}

Agrawal, P. B., Narang, A., and Kumar, P. (1996). Fluconazole. Indian J. Pediatr. 63, 775-780. doi: 10.1007/BF02730928

Alicic, R. Z., Rooney, M. T., and Tuttle, K. R. (2017). Diabetic kidney disease: challenges, progress, and possibilities. Clin. J. Am. Soc. Nephrol. 12, 2032-2045. doi: 10.2215/CJN.11491116

Biswal, M., Rudramurthy, S. M., Jain, N., Shamanth, A. S., Sharma, D., Jain, K., et al. (2017). Controlling a possible outbreak of Candida auris infection: lessons learnt from multiple interventions. J. Hosp. Infect. 97, 363-370. doi: 10.1016/j. jhin.2017.09.009

Calvo, B., Melo, A. S. A., Perozo-Mena, A., Hernandez, M., Francisco, E. C., Hagen, F., et al. (2016). First report of Candida auris in America: clinical and microbiological aspects of 18 episodes of candidemia. J. Infect. 73, 369-374. doi: 10.1016/j.jinf.2016.07.008

Centers for Disease Control and Prevention (2021). Candida auris. Avaliable at: https://www.cdc.gov/fungal/candida-auris/index.html (accessed January 16, 2021).

Chowdhary, A., Prakash, A., Sharma, C., Kordalewska, M., Kumar, A., Sarma, S., et al. (2018). A multicentre study of antifungal susceptibility patterns among 350 Candida auris isolates (2009-17) in India: role of the ERG11 and FKS1 genes in azole and echinocandin resistance. J. Antimicrob, Chemother. 73, 891-899. doi: $10.1093 / \mathrm{jac} / \mathrm{dkx} 480$

Chowdhary, A., Sharma, C., Duggal, S., Agarwal, K., Prakash, A., Singh, P. K., et al. (2013). New clonal strain of Candida auris, Delhi, India. Emerg. Infect. Dis. 19, 1670-1673. doi: 10.3201/eid1910.130393

Chowdhary, A., Sharma, C., and Meis, J. F. (2017). Candida auris: a rapidly emerging cause of hospital-acquired multidrug-resistant fungal infections globally. PLoS Pathog. 13:e1006290. doi: 10.1371/journal.ppat.1006290

Chowdhary, A., Voss, A., and Meis, J. F. (2016). Multidrug-resistant Candida auris: 'new kid on the block' in hospital-associated infections? J. Hosp. Infect. 94, 209-212. doi: 10.1016/j.jhin.2016.08.004

Collister, D., Rigatto, C., and Tangri, N. (2017). Anemia management in chronic kidney disease and dialysis: a narrative review. Curr. Opin. Nephrol. Hypertens. 26, 214-218. doi: 10.1097/MNH.0000000000000317

Cortegiani, A., Misseri, G., Giarratano, A., Bassetti, M., and Eyre, D. (2019). The global challenge of Candida auris in the intensive care unit. Crit. Care 23:150. doi: 10.1186/s13054-019-2449-y

Emara, M., Ahmad, S., Khan, Z., Joseph, L., Al-Obaid, I., Purohit, P., et al. (2015). Candida auris candidemia in Kuwait, 2014. Emerg. Infect. Dis. 21, 1091-1092. doi: 10.3201/eid2106.150270

Farina, C., Manso, E., Andreoni, S., Conte, M., Fazii, P., Lombardi, G., et al. (2011). Interlaboratory evaluation of VITEK2 system and Sensititre YeastOne ${ }^{\circledR}$ for antifungal susceptibility testing of yeasts isolated from blood cultures against four antifungal agents. New Microbiol. 34, 195-201.

Healey, K. R., Kordalewska, M., Jiménez Ortigosa, C., Singh, A., Berrío, I., Chowdhary, A., et al. (2018). Limited ERG11 mutations identified in Isolates of Candida auris directly contribute to reduced azole susceptibility. Antimicrob. Agents Chemother. 62:e1427-18. doi: 10.1128/AAC.01427-18

Hosmer, J. D. W., Lemeshow, S., and Sturdivant, R. X. (2013). Applied Logistic Regression, 3rd Edn. Hoboken, NJ: John Wiley \& Sons.

Hou, X., Lee, A., Jiménez-Ortigosa, C., Kordalewska, M., Perlin, D. S., and Zhao, Y. (2019). Rapid detection of ERG11-Associated Azole Resistance and the statistical analysis. SH, FZ, WJ, and YY drafted the manuscript. All authors played a significant role in data collection and analysis.

\section{FUNDING}

This research was supported by the Ministry of Science and Technology of the People's Republic of China (2018ZX10101003 and 2018ZX10712-001).

FKS -Associated Echinocandin resistance in Candida auris. Antimicrob Agents Chemother. 63:e01811-18. doi: 10.1128/AAC.01811-18

Jeffery-Smith, A., Taori, S. K., Schelenz, S., Jeffery, K., Johnson, E. M., Borman, A., et al. (2018). Candida auris: a review of the literature. Clin. Microbiol. Rev. 31:e0029-17. doi: 10.1128/CMR.00029-17

Kathuria, S., Singh, P. K., Sharma, C., Prakash, A., Masih, A., Kumar, A., et al. (2015). Multidrug-Resistant Candida auris misidentified as Candida haemulonii: characterization by matrix-assisted laser desorption IonizationTime of flight mass spectrometry and DNA sequencing and its antifungal susceptibility profile variability by Vitek 2, CLSI Broth microdilution, and etest method. J. Clin. Microbiol. 53, 1823-1830. doi: 10.1128/JCM.00367-15

Kim Hutchings Uke (2018). Candida auris in Healthcare Settings - Europe. Avaliable at: https://www.ecdc.europa.eu/sites/portal/files/documents/RRACandida-auris-European-Union-countries.pdf (accessed Feb 6, 2020).

Kordalewska, M., Lee, A., Park, S., Berrio, I., Chowdhary, A., Zhao, Y., et al. (2018). Understanding echinocandin resistance in the emerging pathogen Candida auris. Antimicrob. Agents Chemother. 62:e0238-18. doi: 10.1128/AAC. 00238-18

Ku, T. S. N., Walraven, C. J., and Lee, S. A. (2018). Candida auris: disinfectants and implications for infection control. Front Microbiol 9:726. doi: 10.3389/fmicb. 2018.00726

Lara, H. H., Ixtepan-Turrent, L., Jose Yacaman, M., and Lopez-Ribot, J. (2020). Inhibition of Candida auris biofilm formation on medical and environmental surfaces by silver nanoparticles. Acs Appl. Mater. Inter. 12, 21183-21191. doi: 10.1021/acsami.9b20708

Larkin, E., Hager, C., Chandra, J., Mukherjee, P. K., Retuerto, M., Salem, I., et al. (2017). The emerging pathogen Candida auris: growth phenotype, virulence factors, activity of antifungals, and effect of SCY-078, a novel glucan synthesis inhibitor, on growth morphology and biofilm formation. Antimicrob. Agents Chemother. 61:e02396-16. doi: 10.1128/AAC.02396-16

Lockhart, S. R., Etienne, K. A., Vallabhaneni, S., Farooqi, J., Chowdhary, A., Govender, N. P., et al. (2016). Simultaneous emergence of multidrug-resistant Candida auris on 3 continents confirmed by whole-genome sequencing and epidemiological analyses. Clin. Infect. Dis. 64, 134-140. doi: 10.1093/cid/ciw691

Madder, H., Moir, I., Moroney, R., Butcher, L., Newnham, R., Sunderland, M., et al. (2017). Multiuse patient monitoring equipment as a risk factor for acquisition of Candida auris. bioRxiv [Preprint]. doi: 10.1101/149054

Meis, J. F., and Chowdhary, A. (2018). Candida auris: a global fungal public health threat. Lancet Infect. Dis. 18, 1298-1299. doi: 10.1016/S1473-3099(18)30609-1

Mejia-Chew, C., O’halloran, J. A., Olsen, M. A., Stwalley, D., Kronen, R., Lin, C., et al. (2019). Effect of infectious disease consultation on mortality and treatment of patients with candida bloodstream infections: a retrospective, cohort study. Lancet Infect. Dis. 19, 1336-1344. doi: 10.1016/S1473-3099(19)30405-0

Muñoz, J. F., Gade, L., Chow, N. A., Loparev, V. N., Juieng, P., Berkow, E. L., et al. (2018). Genomic insights into multidrug-resistance, mating and virulence in Candida auris and related emerging species. Nat. Commun. 9:5346. doi: 10.1038/s41467-018-07779-6

Nancy, A. C., Theun De, G., Hamid, B., Abastabar, M., Chiller, T. M., and Meis, J. F. (2019). Potential fifth clade of Candida auris, Iran, 2018. Emerg. Infect. Dis. 25, 1780-1781. doi: 10.3201/eid2509.190686

Navalkele, B. D., Revankar, S., and Chandrasekar, P. (2017). Candida auris: a worrisome, globally emerging pathogen. Expert Rev. Anti Infect. 15, 819-827. doi: $10.1080 / 14787210.2017 .1364992$ 
Oh, B. J., Shin, J. H., Kim, M. N., Sung, H., Lee, K., Joo, M. Y., et al. (2011). Biofilm formation and genotyping of Candida haemulonii, Candida pseudohaemulonii, and a proposed new species (Candida auris) isolates from Korea. Med. Mycol. 49, 98-102. doi: 10.3109/13693786.2010.493563

Ostrowsky, B., Greenko, J., Adams, E., Quinn, M., O’Brien, B., Chaturvedi, V., et al. (2020). Candida auris Isolates resistant to three classes of antifungal medications - New York, 2019. MMWR Morb. Mortal. Wkly. Rep. 69, 6-9. doi: 10.15585/mmwr.mm6901a2

Palazón-Bru, A., Tomás-Rodríguez, M. I., López-Cascales, M. T. Folgado-de la Rosa, D. M., and Gil-Guillén, V. F. (2017). Multivariate ordered logistic regression models: dealing with the model-building strategy. J. Pediatr. Adol. Gynec. 30:664. doi: 10.1016/j.jpag.2017.06.006

Park, J. Y., Bradley, N., Brooks, S., Burney, S., and Wassner, C. (2019). Management of patients with Candida auris fungemia at community hospital, Brooklyn, New York, USA, 2016-2018. Emerg. Infect. Dis. 25, 601-602. doi: 10.3201/ eid2503.180927

Peduzzi, P., Concato, J., Kemper, E., Holford, T. R., and Feinstein, A. R. (1996). A simulation study of the number of events per variable in logistic regression analysis. J. Clin. Epidemiol. 49, 1373-1379. doi: 10.1016/s0895-4356(96) 00236-3

Rhee, C. M., Ahmadi, S. F., Kovesdy, C. P., and Kalantar-Zadeh, K. (2018). Low-protein diet for conservative management of chronic kidney disease: a systematic review and meta-analysis of controlled trials. J. Cachexia Sarcopenia Muscle 9, 235-245. doi: 10.1002/jcsm.12264

Rhodes, J., Abdolrasouli, A., Farrer, R. A., Cuomo, C. A., Aanensen, D. M., Armstrong-James, D., et al. (2018). Genomic epidemiology of the UK outbreak of the emerging human fungal pathogen Candida auris. Emerg. Microbes Infect. 7:43. doi: 10.1038/s41426-018-0045-x

Rhodes, J., and Fisher, M. C. (2019). Global epidemiology of emerging Candida auris. Curr. Opin. Microbiol. 52, 84-89. doi: 10.1016/j.mib.2019.05.008

Rindidzani, E. M., Craig, C., Sharona, S., and Govender, N. P. (2014). Candida auris-Associated Candidemia, South Africa. Emerg. Infect. Dis. 20, 1250-1251. doi: 10.3201/eid2007.131765

Rybak, J. M., Doorley, L. A., Nishimoto, A. T., Barker, K. S., Palmer, G. E., and Rogers, P. D. (2019). Abrogation of triazole resistance upon deletion of CDR1 in a clinical Isolate of Candida auris. Antimicrob. Agents Chemother. 63:e00057-19. doi: 10.1128/AAC.00057-19

Satoh, K., Makimura, K., Hasumi, Y., Nishiyama, Y., Uchida, K., and Yamaguchi, H. (2009). Candida auris sp. nov., a novel ascomycetous yeast isolated from the external ear canal of an inpatient in a Japanese hospital. Microbiol. Immunol. 53, 41-44. doi: 10.1111/j.1348-0421.2008.00083.x

Shaukat, A., Al Ansari, N., Al Wali, W., Karic, E., El Madhoun, I., Mitwally, H., et al. (2020). Experience of treating Candida auris cases at a general hospital in the state of Qatar. IDCases 23:e01007. doi: 10.1016/j.idcr.2020. e01007

Tan, J., Liu, Z., Sun, Y., Yang, L., and Gao, L. (2019). Inhibitory effects of photodynamic inactivation on planktonic cells and biofilms of Candida auris. Mycopathologia 184, 525-531. doi: 10.1007/s11046-019-00352-9

The New York Times (2019). A Mysteries Infection, Spanning the Globe in a Climate of Secrecy. Avaliable at: https://www.nytsyn.com. (accessed April 6. 2019).

Vatanshenassan, M., Boekhout, T., Meis, J. F., Berman, J., Chowdhary, A., BenAmi, R., et al. (2019). Candida auris identification and rapid antifungal susceptibility testing against echinocandins by MALDI-TOF MS. Front. Cell Infect. Microbiol. 9:20. doi: 10.3389/fcimb.2019.00020

Wang, T., Jia, Y., Chu, B., Liu, H., Dong, X., and Zhang, Y. (2019). Nocardiosis in kidney disease patients under immunosuppressive therapy: case report and literature review. Int. J. Med. Sci. 16, 838-844. doi: 10.7150/ijms. 32440

Conflict of Interest: The authors declare that the research was conducted in the absence of any commercial or financial relationships that could be construed as a potential conflict of interest.

Copyright () $2021 \mathrm{Hu}$, Zhu, Jiang, Wang, Quan, Zhang, Gu and Yang. This is an open-access article distributed under the terms of the Creative Commons Attribution License (CC BY). The use, distribution or reproduction in other forums is permitted, provided the original author(s) and the copyright owner(s) are credited and that the original publication in this journal is cited, in accordance with accepted academic practice. No use, distribution or reproduction is permitted which does not comply with these terms. 